\title{
Dynamic Deformation of Clamped Circular Plates Subjected to Confined Blast Loading
}

\author{
P. W. Chen*, H. Liu*, Y. S. Ding ${ }^{\dagger}$, B. Q. Guo*, J. J. Chen* and H. B. Liu* \\ *State Key Laboratory of Explosion Science and Technology, Beijing Institute of Technology, Beijing I0008I, China \\ tInstitute of Mechanics, Chinese Academy of Sciences, Beijing I00190, China
}

\begin{abstract}
In this paper, the dynamic deformation of thin metal circular plates subjected to confined blast loading was studied using highspeed three-dimensional Digital Image Correlation (3D DIC). A small-scale confined cylinder vessel was designed for applying blast loading, in which an explosive charge was ignited to generate blast loading acting on a thin metal circular plate clamped on the end of the vessel by a cover flange. The images of the metal plates during the dynamic response were recorded by two high-speed cameras. The 3D transient displacement fields, velocity fields, strain fields and residual deformation profiles were calculated by using 3D DIC. Some feature deformation parameters including maximum out-of-plane displacement, final deflection, maximum principal strain and residual principal strain were extracted, and the result was in good agreement with that simulated by AUTODYN. A dimensionless displacement was introduced to analyse the effects of plate thickness, material types and charge mass on the deflection of metal plates. DIC is also proven to be a powerful technique to measure dynamic deformation under blast loading.
\end{abstract}

KEY WORDS: 3D Digital Image Correlation, Blast loading, Dynamic deformation, Thin metal plates

\section{Introduction}

Plated structures are important in a variety of aero, marine and land-based applications including aircrafts, ships, bins and bunkers, which may be subjected to a blast loading due to the attack of missiles and explosion charges [1]. For instance, the complete loss of an aircraft can be caused by the internal explosion of explosive devices in the commercial aircraft. For the large-scale structures and vehicles, frames and stringers are riveted or adhesively bonded to the thin metal fuselage skin. The curvature of the fuselage is small compared to the whole shell size, and so the individual panels can be considered as flat panels [2, $3]$. The surface deformation measurement of the plate structures subjected to blast loading is an important task of experimental solid mechanics. Understanding the nonlinear dynamic response of the plate structures can provide some important references for designing.

The response of clamped plate structures subjected to air and underwater blast loadings has been widely studied. Nurick et al. [4-6] presented the theoretical and experimental studies on the failure of plates subjected to the localised or uniform blast loads. It was shown that the permanent mid-point deflection increased with increasing impulse, resulting in thinning at the boundary. Thomas et al. studied the effect of different edge fixations on mild steel plates subjected to air uniform blast loads [7]. The mid-point deflections of two types of plates were approximately the same when the plates did not show tearing. Tearing along the boundary occurred at lower impulses for built-in plates than for clamped plates. The effect of stand-off distance and charge mass on the response of fully clamped circular mild steel plates subjected to blast loads was reported by Jacob et al. [8]. The localization of the blast load on the plate for stand-off distances less than the plate radius resulted in a shape localization such that an inner dome superimposed on a larger global dome resulted from uniform loading. Some modifications on the empirical relationships between stand-off distance and plate deformation were introduced to account for the effect of stand-off distance on plate deformation. Predicting either the response of the plate or the characteristics of the blast loading was attempted when the explosion was partially confined. Although the effect of many experimental conditions (the boundary condition and the impulse) on the deformation of a plate subjected to free-field explosion has been studied, these tests were typically based on posttest measurements of residual single-point deflection and qualitative plate shape.

Conventional measurement techniques, such as strain gauges, VISAR or DISAR, can only provide limited motion or deformation information for a single point or a few points at the same time. Various full-field non-contact optical methods, including interferometric techniques (holography interferometry, speckle interferometry, moiré interferometry etc.) and non-interferometric techniques (e.g. grid method) have been developed and applied to surface measurement. Digital image correlation (DIC), first proposed by Yamaguchi [9], Peter and Ranson [10] in the 1980s, has been considered as one of the most popular and important optical techniques for full-field motion, deformation and shape measurements in the field of experimental mechanics. Compared to the widely used pointwise strain gauge technique, the full-field measurement techniques have many advantages: the strain gradients and hot spots are easy to be acquired particularly 
for the non-homogeneous and anisotropic materials, the results are compatible with finite element analysis software and the facilitate verification and iteration of models, and the technique has much wider applicability [11]. Use of full-field deformation and motion measurements throughout the transient loading regime would significantly improve the assessment of the quality of model predictions, and also provide baseline data to improve the theoretical analyses, especially for blast loading studies. Comparing with other optical methods, DIC technology also has many advantages: white light source, simple optical path, digital collection and high dynamic range [12].

The 2D correlation algorithm of the DIC method was completed by Sutton et al. [13] and was used to measure the in-plane displacement on the surface of the object. He et al. [14] measured the in-plane velocity that occurred in a specific laminar-flow case. Wu et al. [15] measured the basic mechanical properties of retina in simple tension. Some improvement has been done to acquire the out-of-plane deformation [16, 17]. Luo et al. set a pair of CCD cameras to acquire the images of object [18]. The principle of a binocular stereo vision system was combined with DIC for the first time, and the 3D deformation of non-plane object was calculated. A new camera calibration method was then proposed by Helm et al. [19] to simplify the calibration process.

With the development of high-speed photography technology, the optical technique was capable to measure the time-resolved, 3D kinematic fields during the dynamic test by using two high-speed digital cameras 3D DIC technique [20, 21]. Cooper et al. [20] used the high-speed DIC method to observe the motion of a spherical shell at detonation time scales with an ultra-high speed at 1 million $f p s$ (frames per second). The surface features of the spherical shell were recorded during the expansion process along with evidence of fracture nucleation and the subsequent emergence of gaseous detonation products. Franco et al. [21] investigated the deformation of aquarium-like structures with one side made from Al 6061-T6 in watertamped explosive experiments using DIC technology. Tiwari et al. [22] quantified the dynamic response of a sample plate during buried blast loading using the DIC method and combined the Cowper-Symonds constitutive relation with full-field strain and strain rate measurements to define the yield boundaries on the plate surface during blast loading. Arora et al. [23] investigated the resistance of GFRP sandwich panels and laminated tubes to blast in air and underwater environments using high-speed photography and the DIC method. The DIC method was also employed to study dynamic processes under impact loading in other literatures [24, 25].

The instrumentation difficulties and prohibitive cost of large-scale blast testing often result in limited experiments and even more limited data. Although not able to completely replace full-scale testing, laboratory-scale experiments nonetheless provide unique data collection opportunities and new insights into the physical phenomena [25]. This paper presents a laboratory-scale experimental system consisting of a confined cylinder vessel and a high-speed photography system. Confined blast loads were acted on a thin metal circular plate clamped on the end of the vessel by a cover flange. The time-resolved 3D fullfield deformations of different metal plates subjected to confined blast loads were measured using the DIC technique. Numerical simulation of the dynamic responses of the metal plates was also carried out using AUTODYN finite element code, and the results were compared to the DIC measurements. The dimensionless displacement curves of all tests were plotted to analyse the effects of experimental conditions on the dynamic responses of circular plates subjected to confined blast loading.

\section{Principle of DIC}

The principle of DIC is based on the correspondence of the distribution of grey values in a rectangular area (subset) in the picture taken of the specimen in the undeformed state with the distribution of grey values of the same area in the picture taken of the deformed specimen [20]. Through mathematical comparison of two sub-images from a larger pair of displaced images, the motion and deformation of the subsets can be calculated [26, 27].

The 3D DIC system is based on the principles of stereo triangulation, different with the two-dimensional DIC method, whereby the stereo profile of a specimen can be reconstructed using two cameras. Figure 1 shows the principle diagram of stereo triangulation; $x_{m} y_{m} z_{m}$ is the world coordinates; $x_{C 1} y_{C 1} z_{C 1}$ and $x_{C 2} y_{C 2} z_{C 2}$ are the imaging coordinates of two cameras respectively; $M_{1}$ and $M_{2}$ are projection points of $\boldsymbol{M}$ on the imaging planes of the two cameras. The position of point $\boldsymbol{M}$ can be located by searching the intersection point of lines $O_{C 1} M_{1}$ and $O_{C 2} M_{2}$. Therefore, a camera calibration process is necessary before a test, whereby the internal and external parameters of the camera system can be acquired [23]. The parameters include the position of the cameras relative to each other and the internal distortion of each camera.

The stereo matching is another key step in the 3D DIC method. Two cameras are focused on the same area of the observing plate, and two groups of synchronised images for the left and right camera are obtained. According to the calibration coordinates and parameters of the two cameras, the 3D surface contour can be reconstructed by stereo matching the left and right images.

Through the mathematical comparison of two sub-images from a large pair of displaced images, the displacement of the subsets can also be calculated. In the Euler coordinate system shown in Figure 1, the object point $\boldsymbol{M}$ on the 


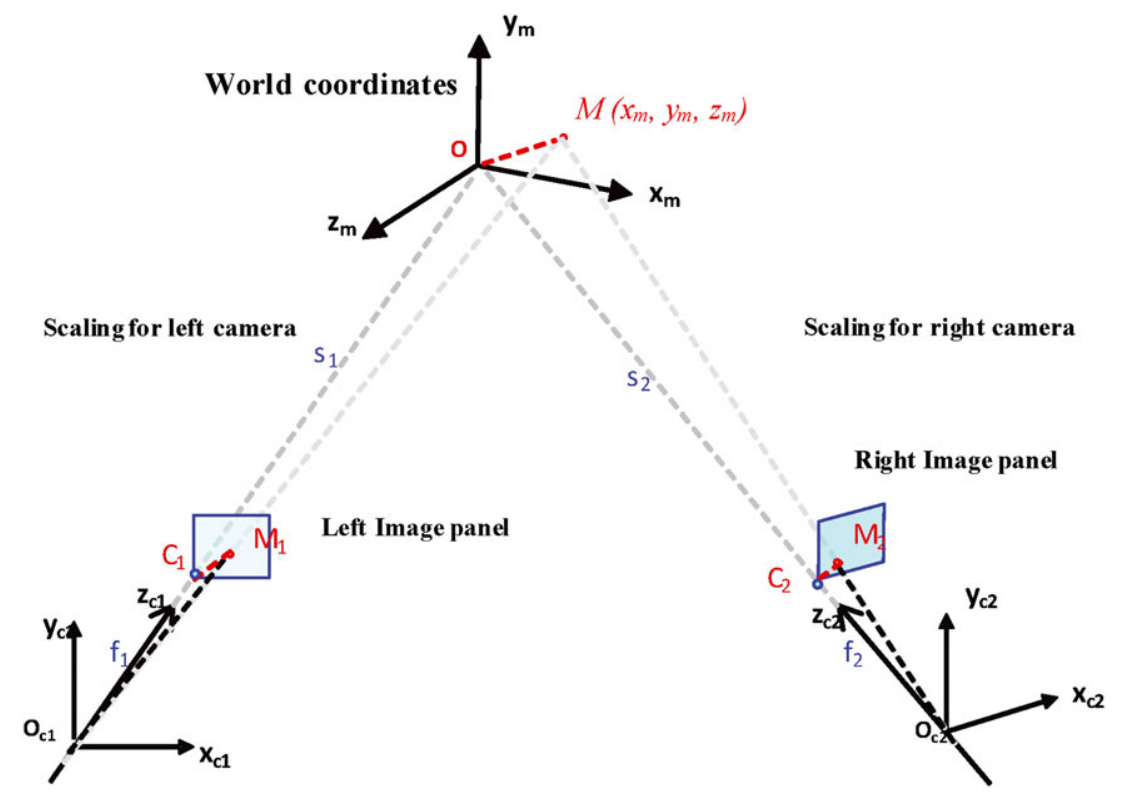

Figure I: Principle diagram of binocular stereo imaging system

specimen surface is defined as $\left(x_{m}, y_{m}, z_{m}\right)$, and the object displacements are defined as $(u, v, w)$ in the $\left(x_{m}, y_{m}, z_{m}\right)$ directions. The velocity components are calculated by using the first-order forward-finite difference, namely, $\left(u,{ }^{\otimes} . v, . w\right)$ [22]. Based on the full-field displacement, the full-field strain distributions can be further calculated by differentiating the obtained displacement fields using appropriate numerical differentiation methods [28].

\section{Experiment and Numerical Simulation}

\section{Experimental details}

In this study, three types of metals of thin circular plates were chosen to study, including: ASTM C11000 copper, h62 brass and $\alpha$-titanium alloy ( $\mathrm{Ti} 50 \mathrm{~A}$ ). The material properties of the tested materials shown in Table 1 were obtained through quasi-static tensile tests and open literature [29], where $\rho$ is the density, $E$ is the Young's modulus, $v$ is the Poisson's ratio and $\sigma_{y}$ is the static tensile yield stress.
The diameter of the thin circular metal plates is $200 \mathrm{~mm}$ and the thickness is 2 or $3 \mathrm{~mm}$. Table 2 lists the thickness and material of the metal plates. Before preparing the random speckle pattern of samples, cleaning and polishing of the specimen surface are necessary. The speckle quality of the samples has a direct effect on the final measurement results. To obtain high quality images, a high contrast speckle pattern was prepared on the metal plate by spraying white paint first and then marking the random points using a black marker pen on the plate surface. When seen by the two cameras, the black speckle dots have a diameter of approximately 5 pixels, which is thought to be perfect for random high-contrast patterns [30].

The experimental set-up is shown in Figure 2. A smallscale confined cylinder vessel was designed to not only apply blast loads but also confine the products and light generated in the explosion. The upper end of the vessel was made of an annular flange, and the bottom was made of a welded metal base. The material of the vessel body was stainless steel. The cylinder vessel had an inner diameter of $170 \mathrm{~mm}$, an external diameter of $200 \mathrm{~mm}$ and a depth of

Table I: Mechanical properties of the tested materials

\begin{tabular}{|c|c|c|c|c|c|}
\hline Material property & Symbol & Unit & Cl I000 copper & h62 brass & Ti 50A \\
\hline Density & $\rho$ & $\mathrm{kg} / \mathrm{m}^{3}$ & 8930 & 8500 & 4500 \\
\hline Young's modulus & $E$ & $\mathrm{GPa}$ & 128 & 93 & 113 \\
\hline Poisson's ratio & $v$ & - & 0.34 & 0.346 & 0.361 \\
\hline Static yield stress & $\sigma_{y}$ & $\mathrm{MPa}$ & 205 & 130 & 320 \\
\hline
\end{tabular}


Table 2: Summary of material, thickness and blast loading conditions of thin plate samples

\begin{tabular}{|c|c|c|c|c|c|}
\hline Sample number & Material & Thickness(mm) & Mass of charge(g) & Peak overpressure $P_{0}(\mathrm{MPa})$ & Explosive impulse $I_{0}(\mathrm{~Pa} \cdot \mathrm{s})$ \\
\hline । & CI I000 copper & 2.00 & 3.00 & 13.0 & 171.5 \\
\hline 2 & Cl I000 copper & 2.00 & 3.50 & 14.7 & 186.8 \\
\hline 3 & Cl I000 copper & 2.00 & 4.00 & 16.5 & 201.5 \\
\hline 4 & Cl I000 copper & 3.00 & 3.00 & 13.0 & 171.5 \\
\hline 5 & CI IO00 copper & 3.00 & 4.00 & 16.5 & 201.5 \\
\hline 6 & h62 brass & 2.00 & 3.00 & 13.0 & 171.5 \\
\hline 7 & h62 brass & 2.00 & 4.00 & 16.5 & 201.5 \\
\hline 8 & Ti 50A & 2.00 & 3.00 & 13.0 & 171.5 \\
\hline 9 & Ti 50A & 2.00 & 4.00 & 16.5 & 201.5 \\
\hline
\end{tabular}

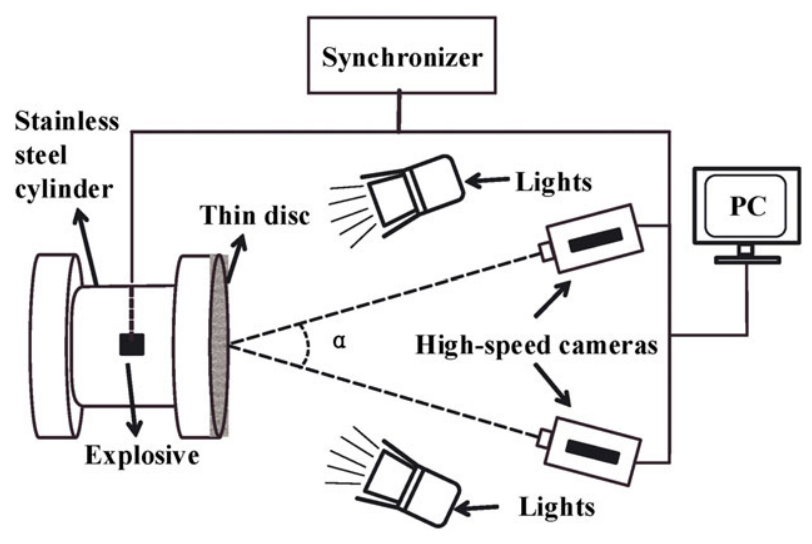

Figure 2: Schematic of the experiment set-up

$200 \mathrm{~mm}$. A thin metal circular plate was fixed on the upper end of the vessel by an annular fixture with a diameter of $240 \mathrm{~mm}$. In this paper, the plate was clamped by the bolts and the cover flange, different with the fully clamped condition. As shown in Figure 3, the bolts do not go through the specimen at the edge, and the plate can slip in-plane from the clamped region towards the exposed region during blast loading. It was reported that the clamping depth had

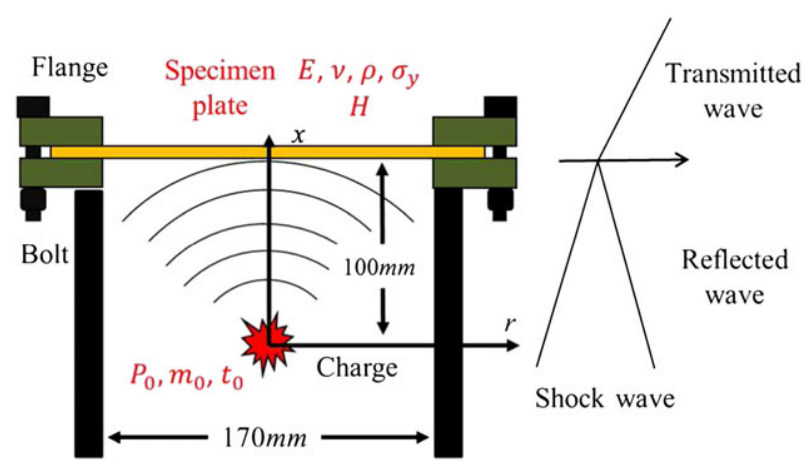

Figure 3: Sketch of blast loading upon a clamped plate no influence on the maximum plate deformation [31], so the effect of the clamping depth was not considered here. By using this vessel, the effects of the charge mass, the plate thickness and the plate materials on the deformation of the specimens can be easily considered. During the test, the boundary areas of the specimens are invisible because they are covered by the flange. The diameter of the exposed portion of the specimen surface was $170 \mathrm{~mm}$, equal to the inner diameter of the vessel.

Two Photron Fastcam SA5 high-speed digital cameras were mounted in a stereo configuration (with an angle is about $15^{\circ}$ to $30^{\circ}$ ) to record the pairs of images during the blast loading. The cameras were positioned at a distance of $0.8 \mathrm{~m}$ from the plate. To maximise the common field of view (FOV) and the level of correlation, the two cameras were rotated and focused. All of the images were outputted and stored with 8 bit of quantization. Two halogen lamps of $1 \mathrm{kw}$ were used as the lighting source.

The camera system was calibrated before the test. In the calibration process, a calibration panel with a series of dots on a flat surface was used as the reference object. A proper sized calibration panel is one that fills the FOV [32]. According to the spacing between the dots, 5 to 20 pairs of the calibration panel images were analysed to acquire the calibration coordinates and parameters of the camera system. The error of measurement in test can be reduced by obtaining a good calibration result. In this paper, calibration plates (by CSI Corporation) with a spacing of $6 \mathrm{~mm}$ were used to calibrate the stereo-vision system. The numbers of dots along the horizontal and vertical axis were 12 and 9, respectively. The angle between the directions of optical axes of two cameras was $24^{\circ}$, and the length of the stereoscopic photograph baseline was $672 \mathrm{~mm}$.

A desensitised RDX cylinder explosive charge with a mass about 3 to $4 \mathrm{~g}$ and a diameter of $20 \mathrm{~mm}$ was placed at the centre of the cylinder vessel and initiated by a detonator. The distance between the explosive charge and the metal 
plate was $100 \mathrm{~mm}$ (labelled as $R_{0}$ ). The explosive charge and two high-speed cameras were synchronically triggered. The framing rate of the two cameras was $50000 \mathrm{fps}$, and the image resolution was $512 \times 272$ pixels. To obtain images with relatively high resolution, a central symmetric area of the metal plate was chosen as the FOV. VIC-3D software (developed by Correlated Solutions, Inc., Columbia, SC 29063, USA) was used to conduct the full-field analysis.

\section{Blast parameter estimation}

Blast parameters are primarily dependent on the amount of energy released by a detonation in the form of a blast wave and the distance from the explosion [33]. A universal normalised description of the blast effects can be given by scaling distance relative to $\left(E_{0} / P_{a}\right)^{1 / 3}$ and scaling pressure relative to $P_{a}$, where $E_{0}$ is the release energy (kJ), and $P_{a}$ is the ambient pressure (typically 1 bar) [24]. For convenience, it is general practice to express the basic explosive input or charge mass $m_{0}(\mathrm{~kg})$ as an equivalent mass of TNT. The results are then given as a function of the vertical distance parameter (scaled distance) $Z=R / m_{0}^{1 / 3}$, where $R(\mathrm{~m})$ is the actual effective distance from the explosion point to the interest point.

In free-blast, the blast peak pressure and impulse could be predicted [34]. Based on the scaling law and least square method, Liang et al. [35] proposed an improved formula to calculate the peak overpressure at various locations in a confined vessel blast. The incident peak pressure $P_{0}(\mathrm{MPa})$ and explosive impulse $I_{0}$ (per unit area) (Pa.s) of TNT explosive on a flat head of the explosive vessel can be given as:

$\left\{\begin{array}{l}P_{0}=\frac{0.220}{Z}-\frac{0.175}{Z^{2}}+\frac{2.73}{Z^{3}} \\ I_{0}=633 \frac{m_{0}{ }^{2 / 3}}{R}\end{array}\right.$

where $Z$ is the scaled distance, $Z=R / m_{0}^{1 / 3}$, in $\mathrm{m} / \mathrm{kg}^{1 / 3} ; R$ is the vertical distance between the explosive charge and the flat head; and $m_{0}$ is the charge mass of TNT explosive. The equivalent mass for $1 \mathrm{~g}$ RDX is reported as $1.22 \mathrm{~g}$ of TNT for a confined vessel blast [35].

As shown in Figure 3, a blast source in an open environment generates a shock wave that expands from the charge location as a spherical wave and acts on the plate, causing the deformation of this area. In a confined environment, the vessel wall confines the expansion of the shock wave. With the increasing of the stand-off distance, the loading distribution transforms from localised to uniform. For the convenience of discussion, the blast loading in this investigation is ideally considered as a localised distribution. The above formulas were used to estimate the peak overpressure $P_{0}$ and impulse $I_{0}$ in confined vessel blasts. Explosive impulse is defined as the integral of pressure with respect to time. In the present work, the pressure profile is simply seen as a triangular impulse, i.e. $I_{0}=P_{0} t_{0} / 2$, where $t_{0}$ is the over-pressure duration. The summary of the calculated incident peak pressure $\left(P_{0}\right)$ and incident impulse $\left(I_{0}\right)$ on the plates in all blast tests are listed in Table 2.

\section{Numerical simulation}

Numerical simulation was carried out using ANSYS AUTODYN code. The finite element model for No.1 blast test is shown in Figure 4. The axis-symmetric model consists of thin metal plate, cylinder vessel, air and explosive charge. The air inside the vessel uses Euler elements, indicated by the blue area, and the metal plate and the cylinder vessel use Lagrange elements with an element size of $1 \mathrm{~mm}$. The total number of elements used in this simulation was 517425 . The material model for the plate uses J-C constitutive parameters for copper while that of the vessel and flange uses $\mathrm{J}-\mathrm{C}$ constitutive parameters for stainless steel. The material model for the explosive uses the JWL equation. The flanges and vessel were simplified as rigid bodies and hence described as analytical rigid surfaces. Because of the clamped condition in this investigation, the bolts and the frictional contact were not considered in the

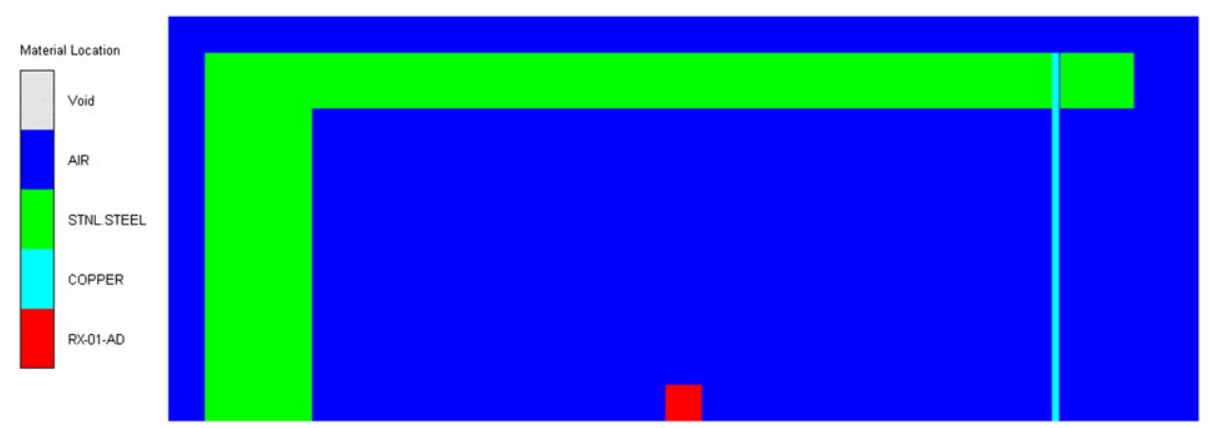

Figure 4: FE model of No.1 blast test 
simulation. The geometric parameters of the model are the same with the No.1 test as shown in Table 2. The parameters of explosive charge used in the simulation were taken from the AUTODYN library shown in Table 3.

\section{Results and Discussion}

\section{Selection of AOI and noise smoothing}

As shown in Figure 5 , a rectangular area about $120 \times 60 \mathrm{~mm}^{2}$ at the specimen centre was selected as the AOI (area of interest) to analyse the deformation fields. The dimension of the AOI was $370 \times 180$ pixels, and the subset size of the correlation calculation was $35 \times 35$ pixels with a step size of 4 pixels. Point $\mathrm{A}(0,0)$ is the geometric centre of the plate. A horizontal straight line $\mathrm{BC}$ through four feature points, A $(0,0), E(-40 \mathrm{~mm}, 0), \mathrm{D}(-20 \mathrm{~mm}, 0)$ and B $(-60 \mathrm{~mm}, 0)$, were selected to conduct line profile analysis of deformation.

\section{Displacement fields}

Figure 6 shows the evolution of out-of-plane displacement (W) fields of the surface of the No.2 specimen (2-mm thickness, C11000 copper and $3.5 \mathrm{~g}$ RDX) at different moments. At $4.96 \mathrm{~ms}$, a visible circular deformation region can be found in the centre of the AOI, and then the size of the deformation region increases with time. The circular deformed area rapidly spreads to the boundaries of the AOI along the radial direction until $5.14 \mathrm{~ms}$. It can be seen that out-of-plane motions during the early period of the blast loading appear in the centre of the plates, demonstrating that shock waves first act on the plate centre. The shape of the deformed region evolves into an approximately symmetric dome shape, and the maximum out-of-plane displacement remains in the plate centre.

The evolution of the out-of-plane displacement profiles along line BC on the No.2 specimen's surface measured by DIC is shown in Figure 7. The results of the numerical simulation are also given for comparison. Because the subsets near the boundary at -85 and $85 \mathrm{~mm}$ are difficult to correlate with the reference subsets, the profiles are plotted from -60 to $60 \mathrm{~mm}$. As indicated in Figure 7, the central area begins to deform earlier than the boundary area (see lines from 4.96 to $5.00 \mathrm{~ms}$ ), and the initial shape of the deformed plate is approximately symmetrical. At $5.78 \mathrm{~ms}$, the displacement of the plate reaches a maximum value in

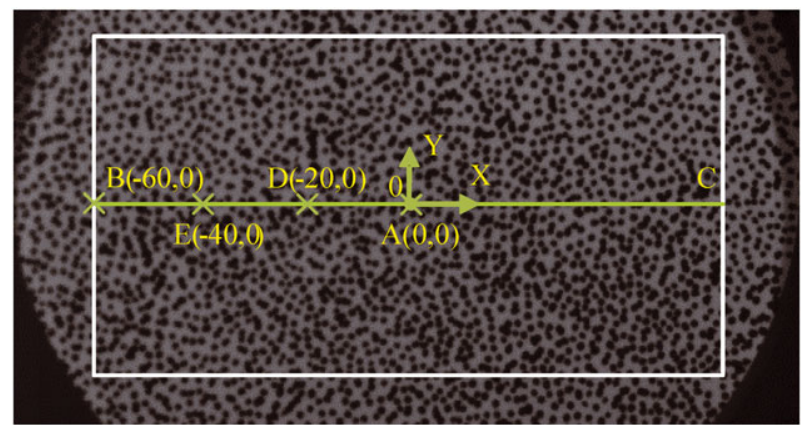

Figure 5: Diagram of speckle computing area

the centre, and then the plate starts to rebound at $6.06 \mathrm{~ms}$ due to elastic recovery. In general, the numerically simulated deflection profile along line BC is in good agreement with the DIC measurement, in spite of divergence in the region near the boundary during the initial stage from 4.96 to $5.12 \mathrm{~ms}$. This is maybe due to the simplification of confinement conditions in numerical simulation, and the friction between the specimen plate and the clamping flanges may be the main source for difference between the experiments and simulation. In addition, in numerical simulation, instantaneous detonation was used to model the reaction of explosives without considering the initiation of electric detonator and propagation of detonation waves, resulted in the difference of shock waves and corresponding forces applied on the metal plates between numerical simulation and real test.

The experimental and simulated displacement histories of feature points A, B, D and E for the No.2 specimen are shown in Figure 8. It can be seen that the out-of-plane displacement curves of the four points have a similar evolution trend. At the initial stage, the out-of-plane displacement increases rapidly due to the initial shock wave loading. After the out-of-plane displacement reaches a peak value, an elastic rebound of the plate occurs, followed by multiple elastic vibrations combined with damping due to multiple incident and reflected shock waves and the inertial effects of the plates. In spite of divergence between the wave peaks and troughs, the vibration frequencies of the simulation result mainly match the experimental results. It is also due to the simplification of confinement conditions in numerical simulation. It can also be seen that point A deforms first,

Table 3: Parameters of explosive charge in the JWL equation

\begin{tabular}{lcccccc}
\hline$\rho /\left(\mathrm{g} \cdot \mathrm{cm}^{-3}\right)$ & $\mathrm{D} /\left(\mathrm{m} \cdot \mathrm{s}^{-1}\right)$ & $\mathrm{e} /\left(\mathrm{KJ} \cdot \mathrm{cm}^{-3}\right)$ & $\mathrm{A} / \mathrm{GPa}$ & $\mathrm{B} / \mathrm{GPa}$ & $\mathrm{R}_{1}$ & $\mathrm{R}_{2}$ \\
\hline 1.185 & 6050 & 4.5 & 172.70 & 596.17 & 4.1 & 1.5 \\
\hline
\end{tabular}


Time: $4.96 \mathrm{~ms}$

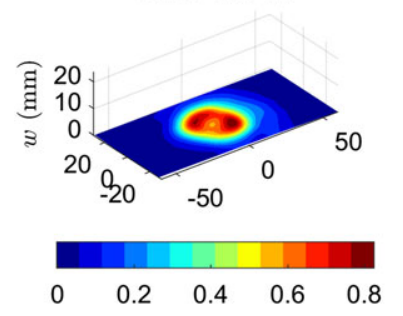

Time: $5.40 \mathrm{~ms}$
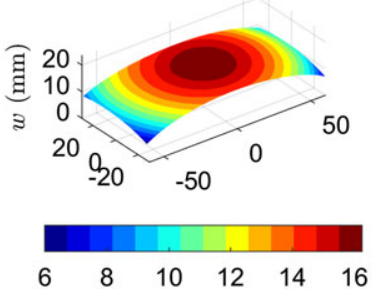

Time: $4.98 \mathrm{~ms}$

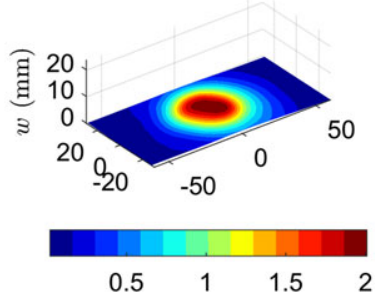

Time: $5.60 \mathrm{~ms}$

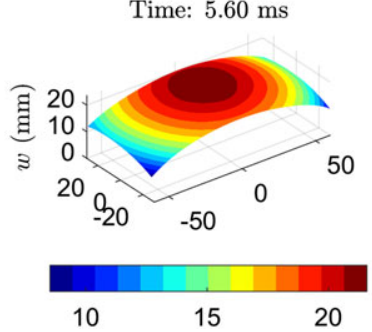

Time: $5.14 \mathrm{~ms}$

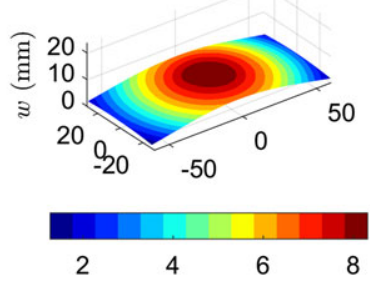

Time: $5.78 \mathrm{~ms}$

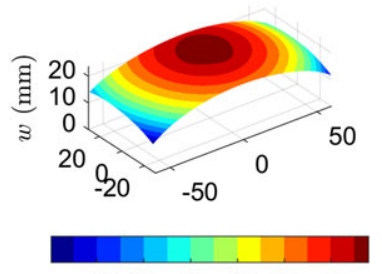

$\begin{array}{llllll}12 & 14 & 16 & 18 & 20 & 22\end{array}$

Figure 6: Evolution of the out-of-plane displacement fields of the No. 2 specimen

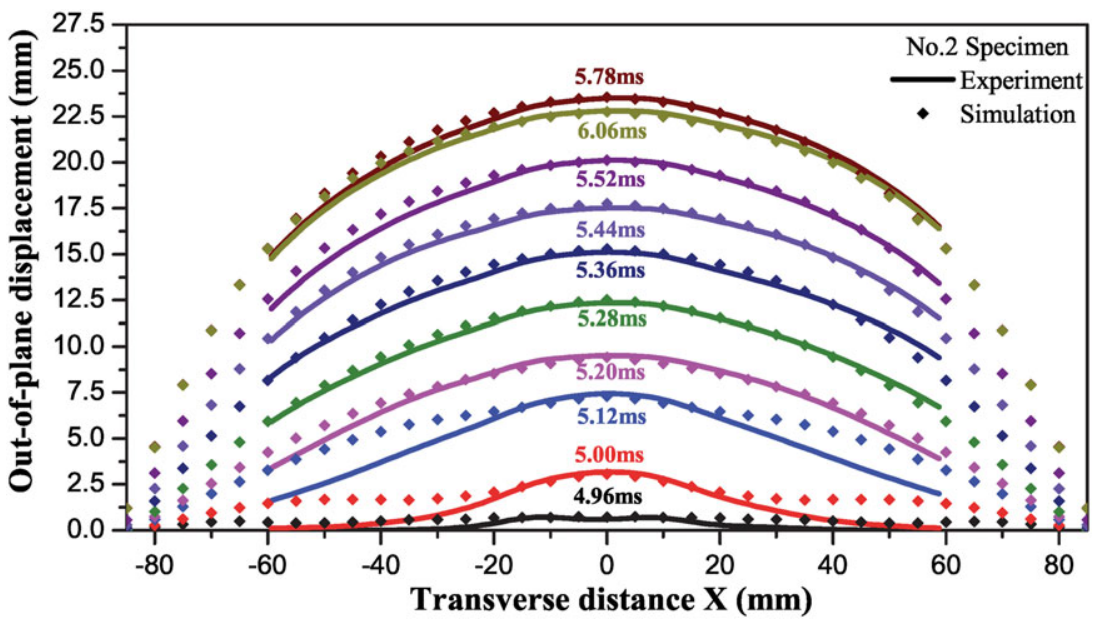

Figure 7: Displacement profile along line BC of the No. 2 specimen

and then points D, E and B deform successively. In the whole process, the maximum out-of-plane displacement is on point $\mathrm{A}$ in the plate centre, while the minimum is on point $B$ near the boundary. The sequence order of out-of-plane displacement values of points A, B, D and E are in agreement with the line profile result indicated in Figure 7. We take the history curve of midpoint A with the largest out-of-plane displacement for further analysis. $\delta_{m}$ is defined as the maximum midpoint out-of-plane displacement, $t_{0}$ is defined as the initial deformation time of the metal plate and $t_{m}$ is defined as the time when the maximum out-of-plane displacement occurs. $t_{e p}$ represents the duration of the initial elastic-plastic deformation, $t_{e p}=t_{m}-t_{0}$. It is also shown that the numerically simulated displacement histories of the four feature points are in good agreement with the DIC measurement in the initial elastic-plastic stage. After the maximum displacement moment, the simulated out-of-plane displacement curves of feature points are close to the experimental results, indicating that the response process at this stage was mainly elastic vibration. The largest difference in the maximum displacement for feature points between the simulated and experimental results is below $1 \mathrm{~mm}$, which is quite satisfactory considering the simplification of explosive detonation and confinement conditions in numerical simulation. This also demonstrates the robustness of finite element tool in simulating the dynamic response of structures under blasting loading. 


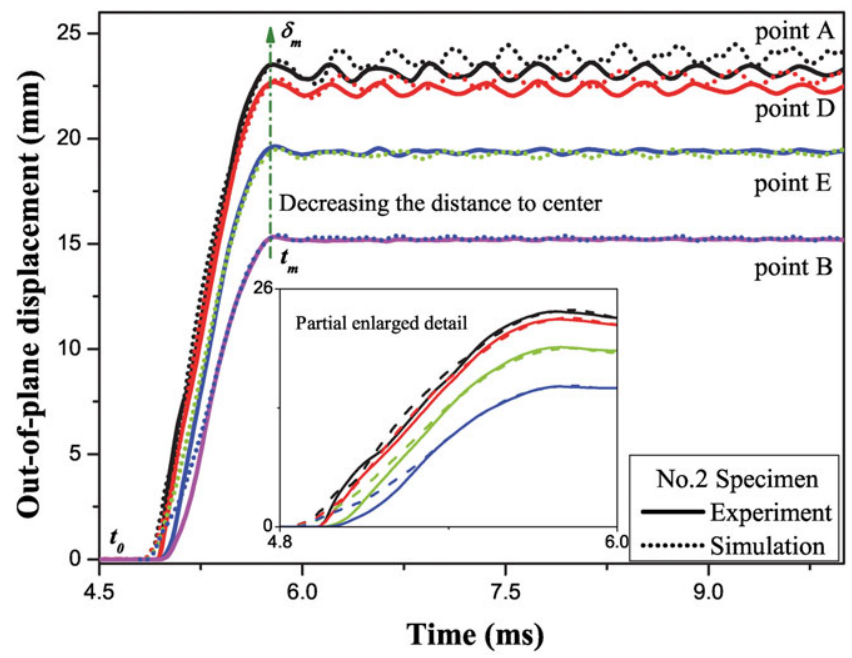

Figure 8: Histories of the out-of-plane displacement $\mathrm{W}$ of feature points of the No. 2 specimen

\section{Velocity fields}

The evolution of the out-of-plane velocity fields of the No.2 specimen (2-mm thickness, C11000 copper and $3.5 \mathrm{~g}$ RDX) surface during the blast at different moments (from 4.96 to $5.82 \mathrm{~ms}$ ) are shown in Figure 9. The evolution of the outof-plane velocity $\mathrm{V}$ profile along line $\mathrm{BC}$ is shown in Figure 10. Similar to the out-of-plane displacement fields, the out-of-plane velocities first appear in the central area of the plate. However, compared to the out-of-plane displacement, the distribution of the out-of-plane velocities is more localised around the plate centre. At approximately $4.98 \mathrm{~ms}$, the highest out-of-plane velocity profile is achieved, while at this moment, the out-of-plane displacement remains quite low (5.44 ms in Figure 7). Then, the out-of-plane velocity decreases rapidly and evolves into a nearly concentric ring shape. Because of the constraints of the fixed boundary, the area close to the plate boundary has a much lower velocity than the central area. The outof-plane velocity of the plate surface drops to nearly zero at approximately $5.78 \mathrm{~ms}$ (in Figure 10), while at this moment, the plate has the largest out-of-plane displacement profile (5.78 ms in Figure 7).

The histories of the out-of-plane velocities of the four feature points A, B, D and E for the No.2 specimen are shown in Figure 11, in which the inset figure illustrates the out-of-plane velocity at the initial stage from $t_{0}$ to $t_{m}$. It can be seen that the out-of-plane velocity rises rapidly in a very short time, reaching a maximum peak velocity of 30 $60 \mathrm{~m} / \mathrm{s}$ at approximately $4.98 \mathrm{~ms}$ and then decreases quickly to zero, followed by multiple vibrations with different amplitudes for different points. It is interesting to note that, after the moment of the maximum velocity at $4.98 \mathrm{~ms}$, the velocity rises again, and a plateau appears before the moment of the maximum displacement $t_{m}(5.78 \mathrm{~ms})$ (see the inset figure of Figure 11). We speculate that this is due to complicated interactions between the reflected shock waves and explosion products. After the moment of the maximum displacement $t_{m}$, multiple vibrations can be clearly observed, which is believed to be the result of elastic recovery. The largest out-of-plane velocity of midpoint A at the plate centre is obviously higher than points $\mathrm{B}, \mathrm{D}$ and E, so we take point A for further analysis. $V_{m}$ is defined as the largest out-of-plane velocity of the plate obtained in the test, and $t_{v}$ is defined as the time when the largest outof-plane velocity occurs.
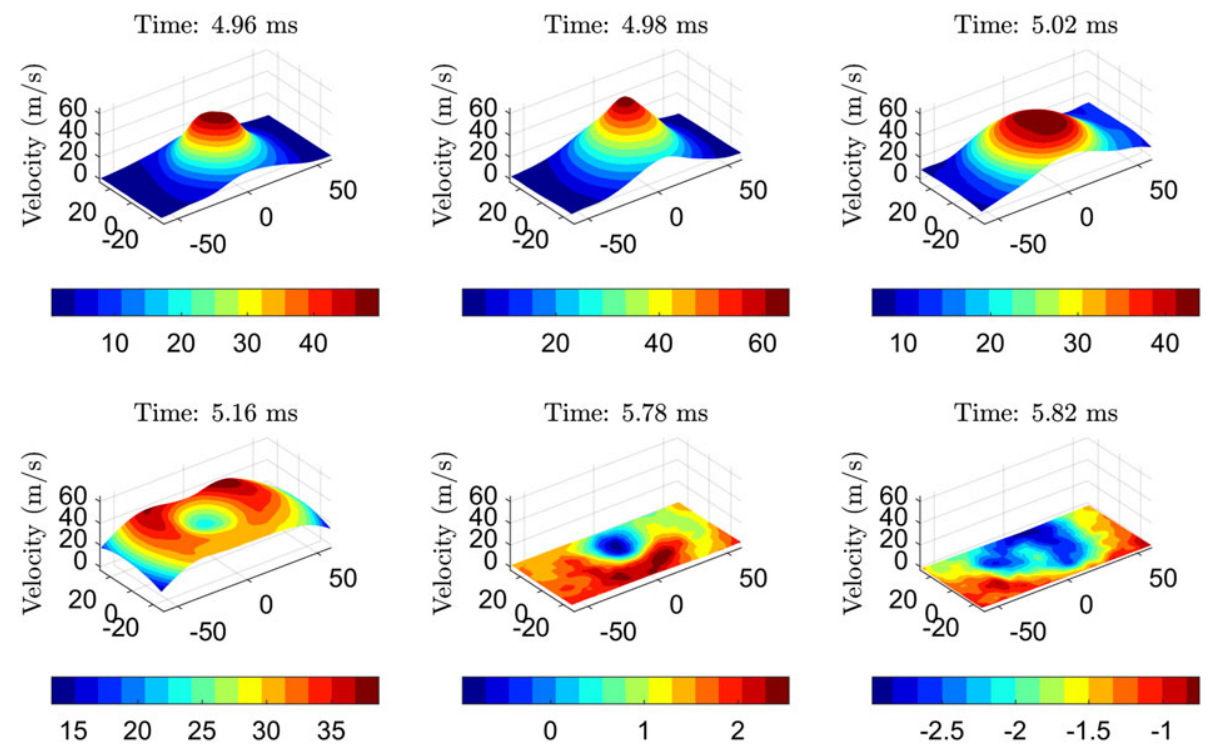

Figure 9: Evolution of the 3D out-of-plane velocity fields for the No. 2 plate 


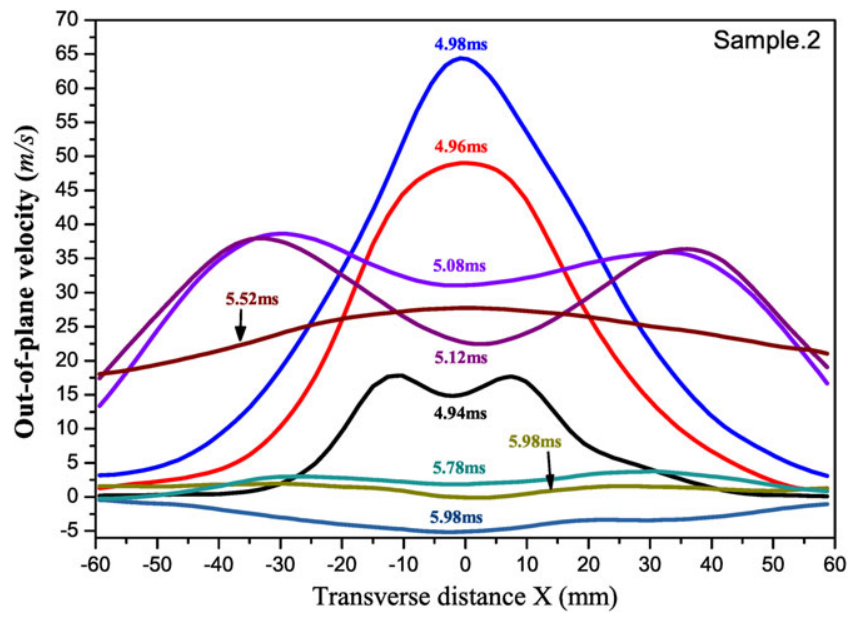

Figure 10: Velocity profile along the line BC for the No. 2 specimen

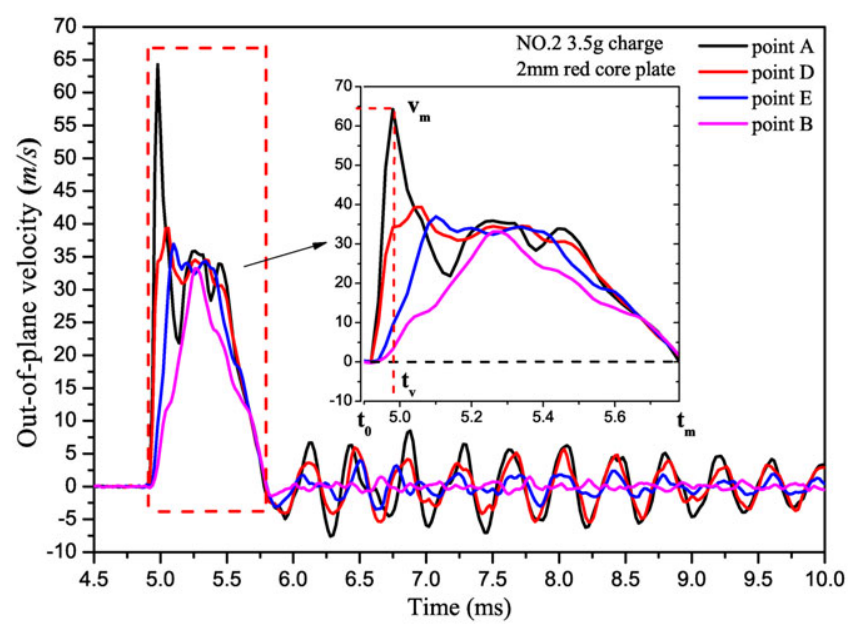

Figure II: Histories of the out-of-plane velocities of the feature points for the No. 2 specimen

\section{Strain fields}

The evolution of the in-plane maximum principal strain fields of the No.2 specimen surface at different moments is shown in Figure 12. The evolution of the in-plane maximum principal strain profile along line $\mathrm{BC}$ is shown in Figure 13, and the histories of the in-plane maximum principal strain of the four feature points $\mathrm{A}, \mathrm{B}, \mathrm{D}$ and $\mathrm{E}$ are shown in Figure 14. It can be seen that the principal strains first occur in the central area of the plate, and then a domeshaped strain localization zone appears in the central area and spreads rapidly outwards to the boundary regions. From $5.24 \mathrm{~ms}$, another concentric strain zone forms near the boundary region and spreads rapidly inwards to the plate centre. The evolution process of the strain zone is similar to the formation of a flying skirt. This dome-shaped deformation zone is also observed in the evolution of the out-of-plane velocities (Figure 9). The principal strains in the boundary area increase rapidly and exceed those in the central region finally. Due to the constraints of the flange, the area close to the clamped region has higher strains than the central area.

\section{Recovering specimens}

The failure of rigidly clamped thin plates under air blast loading has been studied and reported from previous works [36-39]. Menkes et al. [36] identified three main damage modes of blast-loaded beams, namely large inelastic deformation (Mode I), tearing (tensile failure) at the supports (Mode II) and transverse shear failure (Mode III). Smith and Nurick [37] used the three damage modes to analyse the circular plates subjected to uniformly distributed blast loading. Gelman and Marshall [38] redefined Mode I failure as partially necking (Mode Ia) and completely necking (Mode Ib). Nurick and Shave [39] redefined Mode II failure as partial tearing along the boundary (Mode $\mathrm{II}^{*}$ ), failure with increasing mid-point deflection with increasing impulse (Mode IIa) and reducing mid-point deflection with increasing impulse (Mode IIb).

The surface profiles of the metal plate before and after the blast test are shown in Figure 15. The size of the deformed region is equal to the vessel inner diameter of $170 \mathrm{~mm}$. Despite the large deformation, the metal plate did not rupture after the test because the blast loading intensity was not strong enough. It can also be seen that the speckle layer did not peel off during the blast test, demonstrating that the prepared speckle has a strong bonding strength and can withstand the blast loading.

Figure 16 shows photographs of the observing side and rear side of the recovered copper plate after removing the flange. Because the bolts were not assembled through the specimen plate, the friction is not enough to prevent the plate slipping from the clamped region, and an annular trace of sliding between the exposed region and the clamped region can be clearly observed. As shown in Figure 16 (b), some damage marks can be found on the rear side, which is caused by the impact of detonation products and fragments of detonator shell.

After the blast test, the static surface images of the deformed plates were also captured by the cameras system. The permanent deflection fields and residual strain fields for all specimens can be obtained by DIC through mathematically comparisons with the undeformed images. Figure 17 shows the permanent displacement and residual principal strain profiles of the No.2 specimen surface. It can be seen that the final profile of the No.2 specimen was also a dome shape similar to the transient profile described in the 'Displacement fields' section. Figure 17 (b) shows that the plate deformation is localised in the 
Time: $4.96 \mathrm{~ms}$
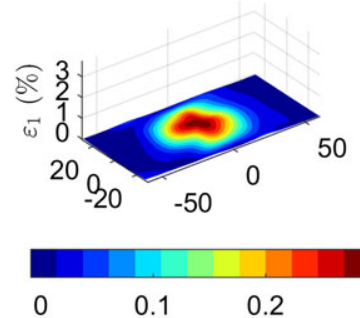

Time: $5.24 \mathrm{~ms}$
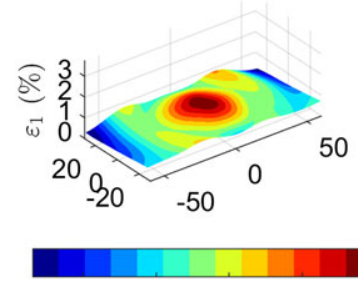

$\begin{array}{llll}0.4 & 0.6 & 0.8 & 1\end{array}$
Time: $5.06 \mathrm{~ms}$
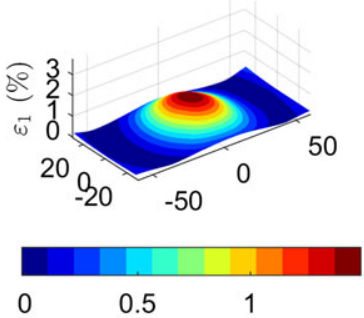

Time: $5.32 \mathrm{~ms}$

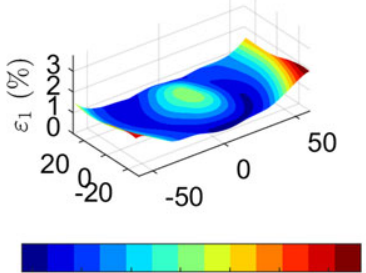

$\begin{array}{lllllll}0.6 & 0.8 & 1 & 1.2 & 1.4 & 1.6 & 1.8\end{array}$
Time: $5.16 \mathrm{~ms}$

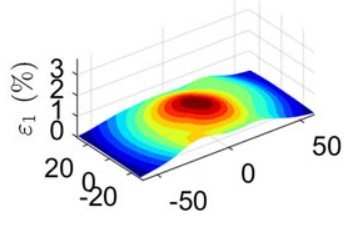

$\begin{array}{llllll}0.2 & 0.4 & 0.6 & 0.8 & 1 & 1.2\end{array}$

Time: $5.84 \mathrm{~ms}$

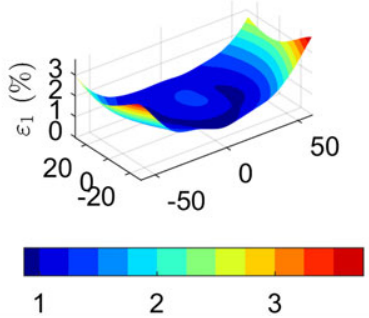

Figure 12: Evolution of the in-plane principal strain fields of the No. 2 plate at different times

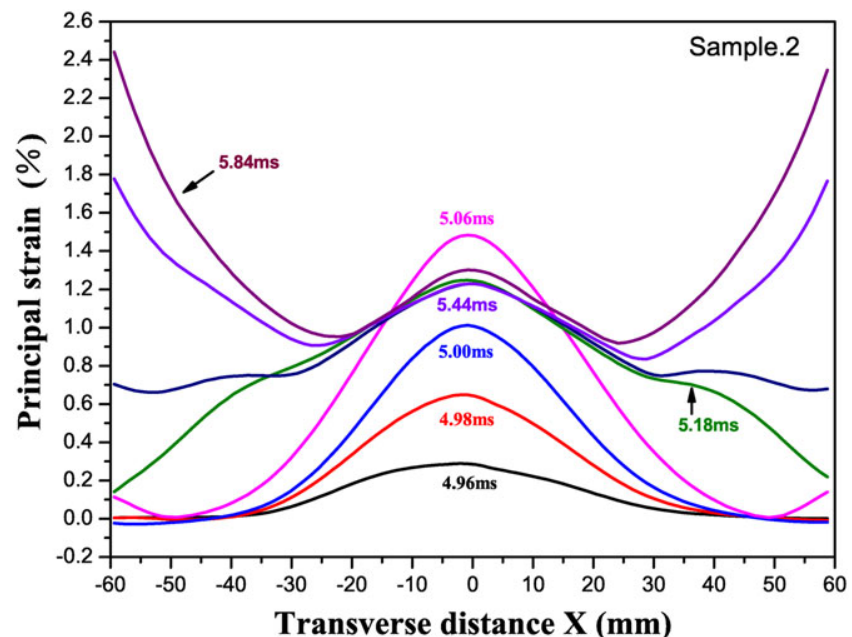

Figure 13: Evolution of the in-plane principal strain profile along line BC for the No. 2 specimen

boundary region of the plate, which is consistent with the transient strain distribution in the end of dynamic response (see Figures 12 and 13).

Figure 18 shows the static surface profiles of the deformed plates along the section line $\mathrm{BC}$ for all specimens after blast tests measured by DIC. The final profiles of all specimens have a similar dome shape. Complete tearing at the boundary (Mode II) and shearing at the boundary (Mode III) were not observed in this investigation. From the recovered plates, the circular ring of thinning was also not observed in the central region of the plate either. Large inelastic deformation (Mode I) was the main damage mode

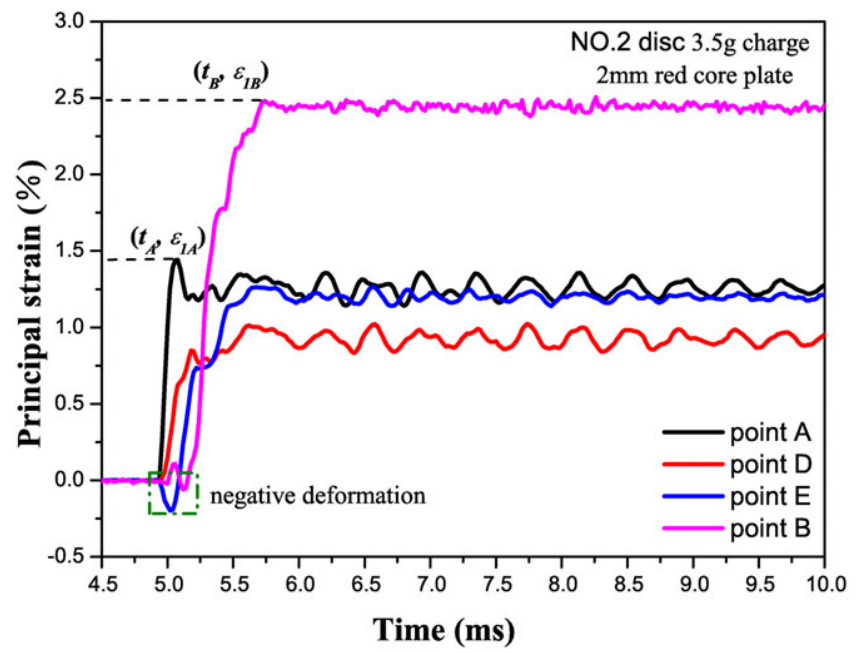

Figure 14: Histories of the in-plane principal strains of feature points for the No. 2 specimen

observed for the thin circular plates subjected to confined blast loading. However if the blast impulse was further increased, causing rupture of the thin metal plates, the other damage and failure modes may occur.

\section{Discussion}

The results of the deformation measurements for all nine tests are summarised in Table 4, including the duration of elastic-plastic deformation $t_{e p}$, the maximum out-of-plane velocity $V_{m}$, the maximum out-of-plane displacement $\delta_{m}$, the peak first effective strain $\varepsilon_{1 A}$, the residual deflection $\delta_{A}$ 
(a)

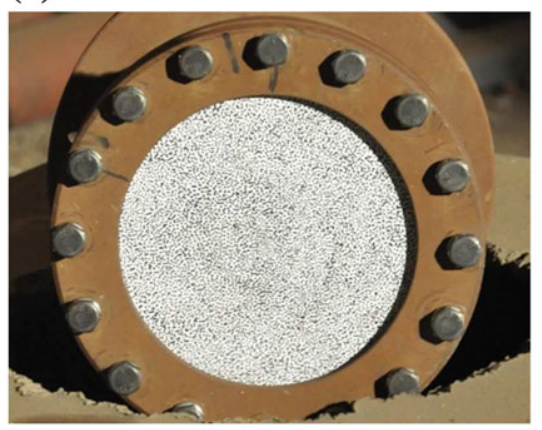

(b)

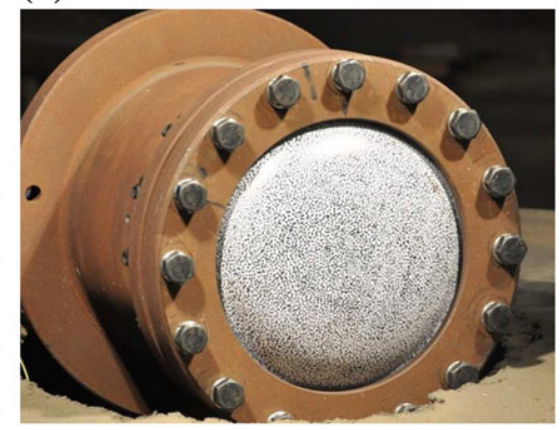

Figure 15: Diagram of the static surface profiles of the No. 2 specimen before and after the blast test: (a) undeformed plate before test and (b) deformed plate after test.

(a)

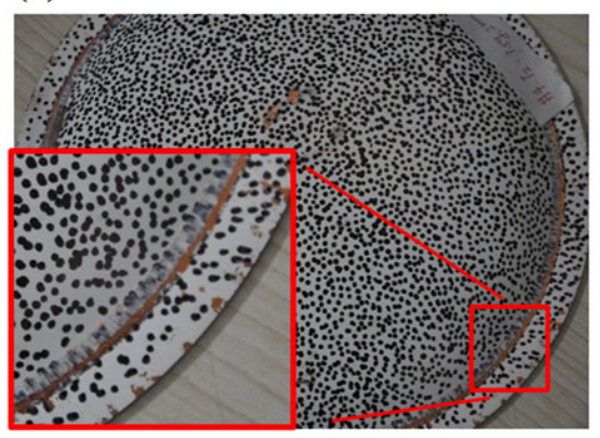

(b)

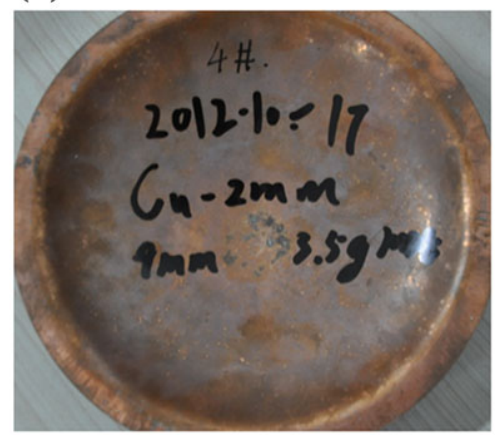

Figure 16: Photographs of the observing side and rear side of the recovered copper plate after the blast test: (a) the observing side and (b) the rear side.
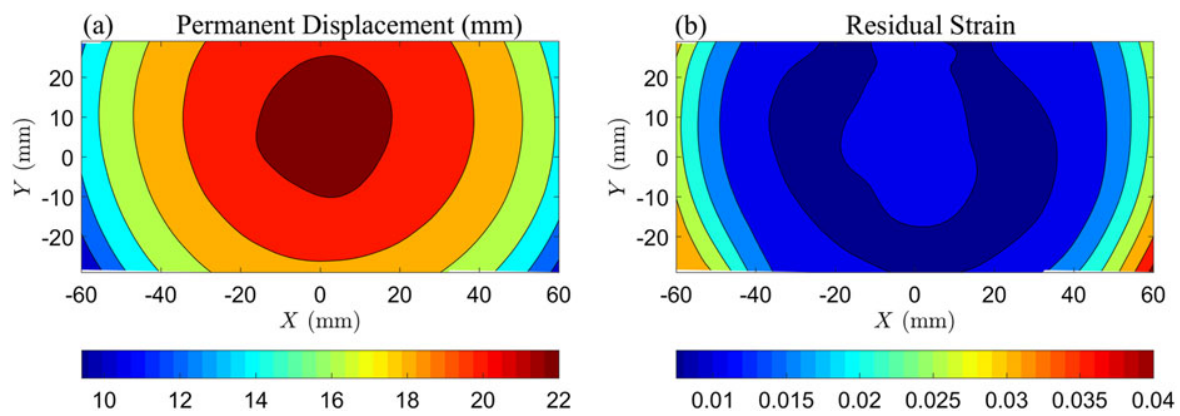

Figure 17: Permanent deformation distribution of the No. 2 specimen after the blast test: (a) residual displacement field and (b) residual principal strain field.

and the residual strain $\varepsilon_{A}$ obtained by DIC. The final deflection $\delta_{t}$ measured by the altimeter is also given for comparison.

To evaluate the accuracy of the measured results, understanding the sensitivity of the DIC method is necessary. The out-of-plane displacement resolution (subpixel accuracy) is considered approximately 0.03 pixel [12], while the resolution of in-plane displacement is 0.01 pixel with higher accuracy. However, Tiwari et al. believe that the out-of-plane measurement accuracy is estimated to be $D / 50,000$, where $D$ is the distance along the viewing direction of a camera to the specimen surface $(D=1 \mathrm{~m}$ in this paper) [22]. The actual out-of-plane measurement error of DIC in this study can be estimated by $\left|\delta_{t}-\delta_{A}\right|$. The relative errors for all tests are from $0.13-0.94 \%$, and the maximum error can reaches $0.21 \mathrm{~mm}$, which are much larger than the predicted error of $0.02 \mathrm{~mm}$ according to the method proposed by Tiwari et al. [22]. Another approach to estimate 


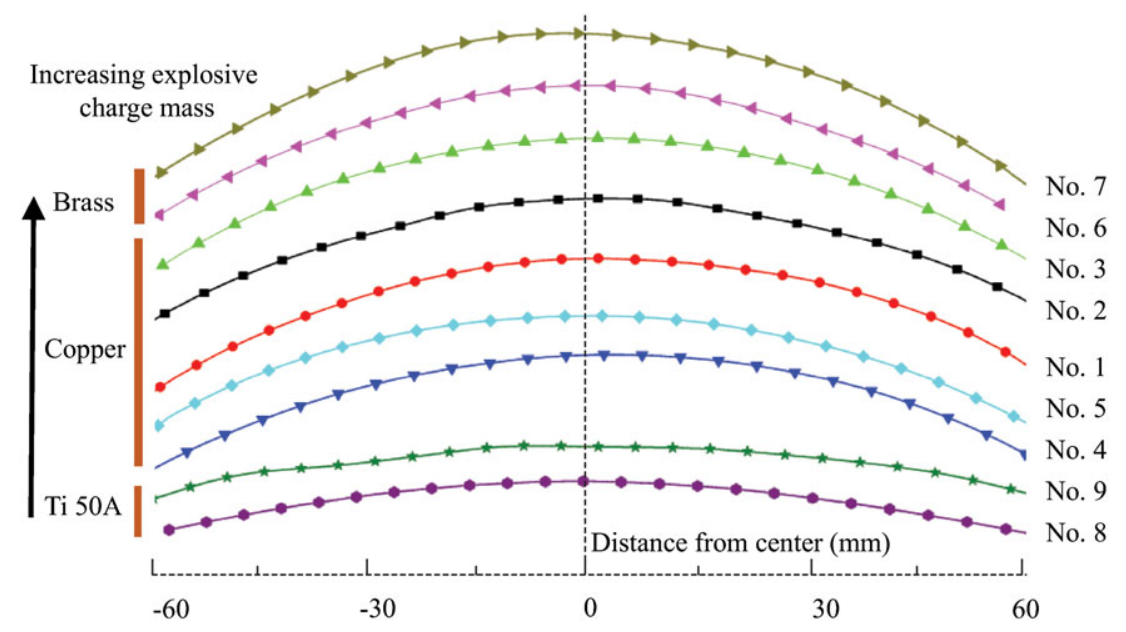

Figure 18: Final surface profiles of the deformed plates along the section line $\mathrm{BC}$ for all specimens after blast tests

Table 4: Summary of deformation measurement results

\begin{tabular}{lccccccc}
\hline No & $\begin{array}{c}t_{\mathrm{ep}} \\
(\mathrm{ms})\end{array}$ & $\begin{array}{c}V_{m}(\mathrm{~m} / \\
\mathrm{s})\end{array}$ & $\begin{array}{c}\delta_{m} \\
(\mathrm{~mm})\end{array}$ & $\begin{array}{c}\delta_{\mathrm{A}} \\
(\mathrm{mm})\end{array}$ & $\begin{array}{c}\delta_{t} \\
(\mathrm{~mm})\end{array}$ & $\begin{array}{c}\varepsilon_{1 \mathrm{~A}} \\
(\%)\end{array}$ & $\begin{array}{c}\varepsilon_{\mathrm{A}} \\
(\%)\end{array}$ \\
\hline 1 & 0.82 & 44.0 & 21.1 & 20.0 & 20.00 & 1.10 & 0.82 \\
2 & 0.82 & 65.0 & 23.5 & 22.1 & 22.64 & 1.44 & 1.23 \\
3 & 0.84 & 73.0 & 24.6 & 23.9 & 24.82 & 1.72 & 1.48 \\
4 & 0.76 & 41.0 & 13.8 & 12.4 & 12.53 & 1.01 & 0.76 \\
5 & 0.76 & 45.8 & 15.4 & 14.1 & 14.32 & 1.12 & 0.82 \\
6 & 0.76 & 71.6 & 22.4 & 22.1 & 22.31 & 1.52 & 1.29 \\
7 & 0.82 & 84.8 & 26.8 & 26.2 & 26.27 & 1.95 & 1.81 \\
8 & 0.30 & 82.4 & 11.5 & 4.5 & 4.55 & 0.82 & 0.36 \\
9 & 0.26 & 108.0 & 12.1 & 5.9 & 6.03 & 1.03 & 0.40 \\
\hline
\end{tabular}

the accuracy is to calculate the standard deviation during image processing. In practical applications, the camera noise is also an important source of the error of 3D DIC method. Therefore, the images of undeformed specimen was analysed under identical settings and conditions. The stand derivation of out-of-plane displacement was found about $0.025 \mathrm{~mm}$, which represents the confidence interval for the match of a certain point in the correlation algorithm. Similar results were also presented by Spranghers et al.[24] .

The deformation of the thin metal plate is largely influenced by the blast loading intensity. For all the three materials used, a larger charge mass generates a higher overpressure, resulting in a larger deformation as shown in Table 4. For instance, for the Nos.1-3 specimens with a 2$\mathrm{mm}$ thickness of copper plate and different charge masses $(2,3.5$ and $4 \mathrm{~g})$, it can be seen that, when the charge mass is increased, $V_{m}, \delta_{m}, \delta_{A}$ and $\varepsilon_{A}$ are all increased. The effects of the thickness of the metal plates can also be observed. In general, the thicker the metal plates, the smaller the deformation. For instance, the Nos. 1 and 4 specimens have the same charge mass of $3.0 \mathrm{~g}$, but a different thickness. When the thickness is increased from 2 to $3 \mathrm{~mm}, V_{m}, \delta_{m}$, $\delta_{A}$ and $\varepsilon_{A}$ are decreased from $44.0 \mathrm{~m} / \mathrm{s}, 21.1 \mathrm{~mm}, 20.0 \mathrm{~mm}$ and $0.82 \%$, respectively, to $41.0 \mathrm{~m} / \mathrm{s}, 13.8 \mathrm{~mm}, 12.4 \mathrm{~mm}$ and $0.76 \%$, respectively. Different materials also exhibit different deformation behaviour under blast loading. The duration of elastic-plastic deformation $t_{e p}$ of C11000 copper and $\mathrm{h} 62$ brass specimens with different thicknesses under different overpressures is in the range of 0.76 to $0.84 \mathrm{~ms}$, much larger than that of Ti 50A titanium alloy specimens $(0.26$ to $0.30 \mathrm{~ms})$. Take for example specimens Nos. 6 and 8 with the same charge mass and the same thickness, but different materials, $\delta_{m}, \delta_{A}$ and $\varepsilon_{A}$ of the No. $6 \mathrm{~h} 62$ brass specimen are $22.4 \mathrm{~mm}, 22.1 \mathrm{~mm}$ and $1.29 \%$, respectively, much larger than those of the No.8 Ti 50A specimen, $11.5 \mathrm{~mm}, 4.5 \mathrm{~mm}$ and $0.36 \%$, respectively.

To further analyse the deformation of clamped metal plates subjected to confined blast loads, a dimensionless displacement $\delta / H$ was introduced. The measured deformation results of the centre point $\mathrm{A}$ are given as an example for further discussion. The plots of the dimensionless displacement $\delta / H$ versus the dimensionless time $t / t_{0}$ at the position of $r=0$ (i.e. the centre point A) for Nos.1, 2, 4, 6 and 8 specimens are shown in Figure 19. The whole deformation process of the clamped thin circular plates subjected to confined blast loading can be divided into two stages: elastic-plastic deformation and vibration with damping. For all tests, the pure elastic duration $t_{0}$ are far shorter than the whole elastic-plastic duration $t_{e p}$, so the effects of the elastic parameters of different materials on dynamic deformation are not considered. However, it is interesting to note that the elastic duration increased with increasing of the dimensionless plate thickness for a constant $R$. For instance, the elastic duration of the No. 4 


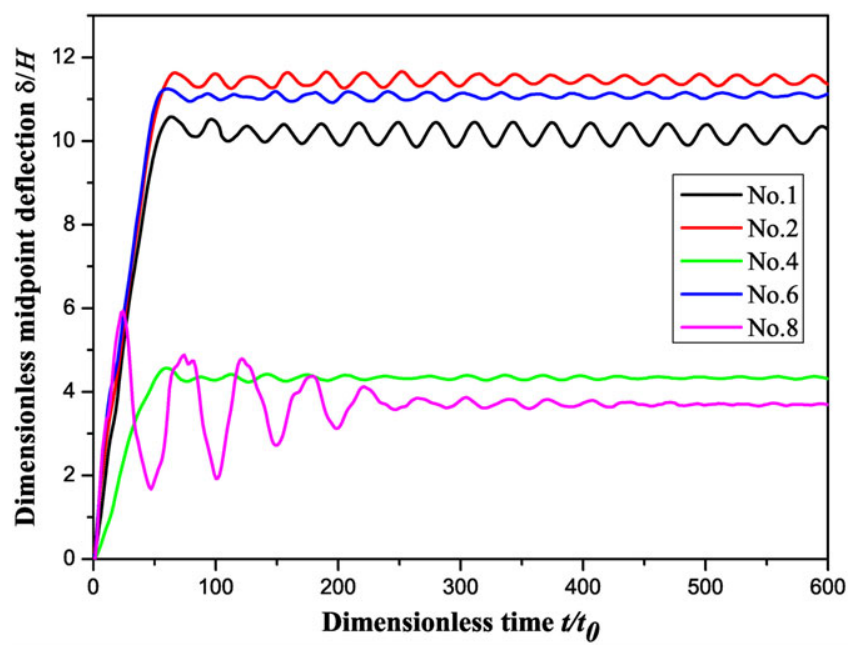

Figure 19: Curves of the midpoint dimensionless displacement $\delta / \mathrm{H}$ versus dimensionless time $t / t 0$

specimen with a 3-mm thickness is longest, and the duration of the other tests of different plate materials with the same thickness of $2 \mathrm{~mm}$ are almost the same. Comparing Nos.1, 6 and 8, it can also be found that the deflection after the elastic-plastic stage (i.e. the baseline of vibration) is proportional to the charge mass. The elasticplastic duration $t_{e p}$ is also different among different materials, and the amplitude of the rebound for Ti $50 \mathrm{~A}$ is much larger than that for the softer materials (copper and brass). The dimensionless transient peak displacement and final residual deflection of Ti 50A are obviously lower than those of $\mathrm{C} 11000$ copper and h62 brass, implying that $\mathrm{Ti}$ $50 \mathrm{~A}$ exhibits better resistance to dynamic deformation than C11000 copper and h62 brass.

\section{Concluding remarks}

The present paper focuses on the dynamic responses of thin circular metal plates subjected to confined blast loads. A small-scale confined cylinder vessel was designed for easily applying blast loads, in which a thin metal circular plate was clamped on the end of the vessel by a cover flange. The dynamic deformation processes of the metal plates were first recorded by two high-speed cameras, and then a fullfield deformation measurement, including transient displacement fields, velocity fields, strain fields and residual deformed profile was conducted using the DIC technique. Some feature deformation parameters including transient maximum out-of-plane displacement, maximum principal strain, final deflection and residual principal strain were extracted based on the DIC measurement. The effects of material properties, dimension of metal plate dimensions (i.e. thickness) and blast loading intensity on the dynamic deformation of the thin metal plates were experimentally investigated.
A simple numerical simulation of the dynamic responses of the metal plates was carried out using AUTODYN code. The simulated out-of-plane displacement profiles and histories were in good agreement with the DIC measurement. Through analysis of the recovered specimens after blast tests, large inelastic deformation (Mode I) was found to be the dominant damage mode in the present study. The dimensionless displacement curves were plotted to further discuss the effects of plate thickness, material types and charge mass on the elastic-plastic deformation and damping vibration of the metal plates.

The experimental results and analysis presented in this paper provide insight into the relationship between the intensity of blast loading, plate dimensions, material properties and the dynamic responses of thin circular metal plates subjected to confined blast loads. DIC is proven to be a powerful technique to measure dynamic full-field deformation of materials and structures under blast loading. The confined blast loading instrumentation combined with the DIC measurement proposed in the paper provides a simple and practical way to evaluate the dynamic behaviour of various materials and structures under blast loading.

\section{Acknowledgements}

This work was supported by the National Natural Science Foundation of China under Grants 11472047, 11472054 and 11521062, the Major Basic Research Program of the Beijing Institute of Technology under Grant 2011CX01030 and the Research Fund for the Doctoral Program of Higher Education of China under Grant 20111101110007.

\section{References}

1. Rajendran, R. L. J. (2009) Blast loadexd plates. Mar. Struct. 22(2), 99-127.

2. En F (1947) A review of underwater explosion phenomena. Compendium of Underwater Explosion Research. ONR1):1-83

3. Veldman, R. L., Ari-Gur, J., Clum, C., Deyoung, A., and Folkert, J. (2006) Effects of pre-pressurization on blast response of clamped aluminum plates. Int. J. Impact Eng. 32(10), 1678-1695.

4. Nurick, G. N., and Martin, J. B. (1989) Deformation of thin plates subjected to impulsive loading - a review .1. Theoretical considerations. Int. J. Impact Eng. 8(2), 159-170.

5. Jacob, N. C. K. Y. S. (2004) Quadrangular plates subjected to localised blast loads - an insight into scaling. Int. J. Impact Eng. 8-9(30), 1179-1208.

6. Teeling-Smith Rg, N. G. (1991) The deformation and tearing of circular plates subjected to impulsive loads. Int. J. Impact Eng. 1 (11), 77-92.

7. Thomas, B. M. (1995) The Effect of Boundary Conditions on Thin Plates Subjected to Impulsive Loads. Doctor, University of Cape Town, Cape Town.

8. Jacob, N., Nurick, G. N., and Langdon, G. S. (2007) The effect of stand-off distance on the failure of fully clamped circular mild 
steel plates subjected to blast loads. Eng. Struct. 29(10), 2723-2736.

9. Yamaguchi, I. (1981) A laser-speckle strain-gauge. J. Phys. E. Sci. Instrum. 14(11), 1270-1273.

10. Peters, W. H., and Ranson, W. F. (1982) Digital imaging techniques in experimental stress-analysis. Opt. Eng. 21(3), 427-431.

11. Schmidt T, Tyson J, Galanulis K (2003) Full-field dynamic displacement and strain measurement using advanced 3D image correlation photogrammetry: part 1., vol 27, pp 47-50

12. Pan, B. (2013) Bias error reduction of digital image correlation using gaussian pre-filtering. Opt. Laser Eng. 51(10), 1161-1167.

13. Sutton, M. A., Wolters, W. J., Peters, W. H., Ranson, W. F., and Mcneill, S. R. (1983) Determination of displacements using an improved digital correlation method. Image Vision Comput. 4 (3), 133-139.

14. He, Z. H., Sutton, M. A., Ranson, W. F., and Peters, W. H. (1984) Two-dimensional fluid-velocity measurements by use of digitalspeckle correlation techniques. Exp. Mech. 24(2), 117-121.

15. Wu, W., Peters, W. H., and Hammer, M. A. (1987) Basic mechanical properties of retina in simple tension. Trans. ASME J. Biomech. Eng. 109(1), 65-7.

16. Sriram, P., and Hanagud, S. (1988) Projection-speckle digitalcorrelation method for surface-displacement measurement. Exp. Mech. 28(4), 340-345.

17. Kahn-Jetter, Z. L., and Chu, T. C. (1993) Three-dimensional displacement measurement using digital image correlation and phtotographic analysis. Exp. Mech. 33(2), 33.

18. Luo, P. F., Chao, Y. J., Sutton, M. A., and Peters, W. H. (1993) Accurate measurement of 3-dimensional deformations in deformable and rigid bodies using computer vision. Exp. Mech. 33(2), 123-132.

19. Helm, J. D., Mcneill, S. R., and Sutton, M. A. (1996) Improved three-dimensional image correlation for surface displacement measurement. Opt. Eng. 35(7), 1911-1920.

20. Cooper MA, Reu PL, Miller TJ (2010) Observations in explosive systems with high-speed digital image correlation.

21. Gagliardi FJ, Cunningham BJ (2010) The use of digital image correlation in explosive experiments. 14th International Detonation Symposium

22. Tiwari, V., Sutton, M. A., Mcneill, S. R., Xu, S., Deng, X., Fourney, W. L., and Bretall, D. (2009) Application of 3D image correlation for full-field transient plate deformation measurements during blast loading. Int. J. Impact. Eng. 36(6), 862-874.

23. Arora, H., Hooper, P. A., and Dear, J. P. (2012) The effects of air and underwater blast on composite sandwich panels and tubular laminate structures. Exp. Mech. 52(1SI), 59-81.

24. Spranghers, K., Vasilakos, I., Lecompte, D., Sol, H., and Vantomme, J. (2012) Full-field deformation measurements of aluminum plates under free air blast loading. Exp. Mech. 52 (9), 1371-1384.

25. Hargather, M. J., and Settles, G. S. (2009) Laboratory-scale techniques for the measurement of a material response to an explosive blast. Int. J. Impact Eng. 36(7), 940-947.

26. Pan, B., and Xie, H. (2007) Full-field strain measurement based on least-square fitting of local displacement for digital image correlation method. Acta. Optica. Sinica 27(2007), 1980-1986.

27. Pan, B., Xie, H. M., Guo, Z. Q., and Hua, T. (2007) Full-field strain measurement using a two-dimensional Savitzky-Golay digital differentiator in digital image correlation. Optical Engineering 46, 0336013.

28. Han, Y., Kim, D., and Kwon, H. (2012) Application of digital image cross-correlation and smoothing function to the diagnosis of breast cancer. J. Mech. Behav. Biomed. 14, 7-18.

29. Jones, N. (1989) Structural Impact. Cambridge Univ. Press Cambridge, UK.

30. Lecompte, D., Smits, A., Bossuyt, S., Sol, H., Vantomme, J., Van Hemelrijck, D., and Habraken, A. M. (2006) Quality assessment of speckle patterns for digital image correlation. Opt. Laser Eng. 44(11), 1132-1145.

31. Bonorchis, D., and Nurick, G. N. (2009) The influence of boundary conditions on the loading of rectangular plates subjected to localised blast loading - importance in numerical simulations. Int. J. Impact Eng. 36(1), 40-52.

32. Helfrick, M. N., Niezrecki, C., Avitabile, P., and Schmidt, T. (2011) 3D digital image correlation methods for full-field vibration measurement. Mech. Syst. Signal Pr. 25(3), 917-927.

33. Smith, P., and Hetherington, J. (1994) Blast and Ballistic Loading of Structures. Butterworth-Hineman, UK.

34. Wu, C. Q., and Hao, H. (2005) Modeling of simultaneous ground shock and airblast pressure on nearby structures from surface explosions. Int. J. Impact Eng. 31(6), 699-717.

35. Liang, D. (2006) Master Dissertation. In: The Study on the Output Characteristic of Composite Explosive and the Dynamic Response of Explosive Vessel (in Chinese). Nanjing University of Science and Technology, Nanjing: 15-31.

36. Menkes, S. B., and Opat, H. J. (1973) Broken beams - tearing and shear failures in explosively loaded clamped beams. Exp. Mech. 13(11), 480-486.

37. Teelingsmith, R. G., and Nurick, G. N. (1991) The deformation and tearing of thin circular plates subjected to impulsive loads. Int. J. Impact Eng. 11(1), 77-91.

38. Nurick, G. N., Gelman, M. E., and Marshall, N. S. (1996) Tearing of blast loaded plates with clamped boundary conditions. Int. J. Impact Eng. 18(7-8), 803-827.

39. Nurick, G. N., and Shave, G. C. (1996) The deformation and tearing of thin square plates subjected to impulsive loads - an experimental study. Int. J. Impact Eng. 18(1), 99-116. 